\title{
Research on the Legal Countermeasures of the College Students' Mass Incidents
}

\author{
Guidong Zeng \\ Xijing University \\ Xi'an, Shaanxi, China \\ Email: 289637641@qq.com
}

\begin{abstract}
The tendency of the growth of the college students' mass incidents reveals that the current countermeasures of the college students' mass incidents are lack of Effectiveness. The effective prevention and resolution of the college students' mass Incidents will impact on the stability and harmony of colleges and universities, and impact on the stability of the whole society. Our country is in the period of social transition, and facing the new situation of the new features of the college students' Mass incidents, the colleges have to rethink and refactor the countermeasures. We should survey the advantages and disadvantages of current countermeasures objectively, and construct the effective, legal countermeasures system based on the Perspective of the constitution and administrative law. At present, the research of the Legal countermeasures of the college students' mass incidents is less and it is not enough systematic. And the research of the legal resolution mechanism of the mass Incidents is thriving. Therefore, we can target and transplant the legal counter measures of the mass incidents into the resolving process of the college students' mass incidents. And it is bound to strengthen the actual effects of the college students' mass incidents. In addition, it will have the positive significance to maintain the harmony and stability of the colleges and universities.
\end{abstract}

Keywords: Students of college; mass incidents; legal countermeasures

\section{THE CONCEPT OF THE COLLEGE STUDENTS' MASS INCIDENTS}

The college students' mass incidents refer to the fact that they are affected by factors such as the international situation, domestic situation, and the management of colleges and universities, which happen in college campuses, and are mainly students in colleges and universities that have no legal basis or legal basis. [1] Collective demonstrations, strikes, strikes, and even the impact of school institutions, occupying school roads hinder school transportation and other types of behavior, which disorder the university's normal teaching and management

\section{THE CHARACTERISTICS OF THE COLLEGE STUDENTS' MASS INCIDENTS}

Compared with group incidents, college students' mass incidents have some common characteristics of group events, such as the commonality of group and appeal, the diversity of incentives, the extreme behavior, the illegality of the methods of struggle, and the protection of rights. Responding to indignation, fortuitousness, suddenness, and unpredictability, destructiveness, reflecting the internal contradictions among the people, it has its own characteristics because of its participation in the subject, time, place of occurrence, precipitating factors, and other reasons.

\section{A. The Participants are College Students}

This is determined by the "college-wide" and "massive" of mass incidents in colleges and universities. Relevant statistics show that the participation rate of university students (ages 19 to 25 ) is more than $90 \%$ in mass incidents in colleges and universities. College students basically aged in this group. The distinctive feature of college students is that they have strong commonalities and belong to the same generation. Compared with other groups, college students are densely populated and easy to come by, and they have the same age, life, learning and thinking, similar life experiences, and culture. Their perplexities of life are basically the same, and the psychological compatibility is strong, and it is easy to produce psychological resonance and herd mentality. Therefore, college students are more likely than other groups to launch mass incidents. [2] Moreover, the young students have determined the irrationality, interaction, and blindness of college students' group incidents.

\section{B. Instability}

The internal cause of college students' mass incidents is that college students are in an incomplete stage of psychological development. Therefore, they are unstable, vulnerable to external factors, and are particularly vulnerable to international and domestic situations. Moreover, college students live in relatively closed groups with strong similarities. Under ubiquitous group pressures and group interaction situations, college students often give up some of their own ideas, values, and behavioral expressions, and follow others. These characteristics of college students determine that they are high-risk groups in mass incidents in colleges and universities, and they also determine that they are most likely to become audiences and participating groups in public emergencies.

\section{Transient}

As college students are in the later period of youth, their psychological characteristics of young people in this period are that they are becoming mature and independent, but at the same time they have psychological instability, impulsivity, and lack of maturity. [3] Usually, They have no rational judgments. Therefore, college students' group events are transient. That is to say, the time for the student gathering is generally shorter. When they realize their 
interest pursuit, the group gathering will dissipate immediately. At the same time, due to the psychological instability, impulsivity and immaturity of college students, their cluster behavior generally has non-violent, purely purposeful, coupled behavioral aggregation, unorganized and other characteristics.

\section{Contradictions Reflected by College Students' Mass Incidents Are Contradictions between Students and Colleges.}

The contradiction between students and students is a concrete manifestation of the internal contradictions among the people. Mass incidents in colleges and universities are a concentrated manifestation of students' right-claiming methods, and they are self-reliant behaviors of students. The survey data shows that the vast majority of students' mass incidents in colleges and universities are now classified as benefit-type (mass-rights) events. Therefore, the incentives for collective events in colleges and universities are still relatively simple, and the absolute majority of incentives are closely related to the college students' own interests and campus security. So it can be seen that most of the college students' collective incidents are caused by simple interest appeals and rights remedies of the college student groups, and that they are subjectively free from malicious disruption of the social order. Contradictions should be internal contradictions among the people. Therefore, college students' mass incidents do not need to be titled with a political perspective and a stable stumbling block in colleges and universities. Instead, they should be regarded as expressions of collective interest appeals of college students, and are opportunities for promoting the adjustment and integration of institutions of higher education and management. It is a conflict that releases the hostile sentiment between students and colleges, which can promote the colleges' stability and safety. Therefore, college students' mass incidents are a concentrated outbreak of disputes among students. Only by improving the school regulations and regulations of institutions of higher learning, smoothing students' interest expression mechanisms, and solving students' problems, can universities and colleges achieve a harmonious relationship by managing according to rules and law, and to maintain the stability of colleges and universities.

E. In the New Media Environment, College Students' Mass Incidents Rapid Radiation, obvious Linkage effects, and wide social influence.

In the new media environment, with the widespread use of Weibo, WeChat and smart phones, the new media technology has greatly reduced the cost of organization, and college students have become "message generation". In students' mass incident of colleges and universities, college students make full use of mobile phones and networks. The use of new media means makes the group events of college students appear to be characterized by rapid radiation and obvious linkage effects. Once a college has a mass incident, in a short period of time, college students connect with other college students through new media means such as smart phones and the Internet. The information is rapidly radiated and spread, which cause more students who are not aware of the truth to be impulsively added, resulting in the scale of mass incidents. The more extended, cross-regional interactions, higher organizational levels, and more pronounced impact on social stability. Due to the characteristics of rapid radiation and obvious linkage effects, the group events of college students further show the variable gender, regional uncertainty, and widespread social influence of event development. [4] It may spread from the campus to the outside of the campus, spread from the city to more other cities, or the contradictory student mass incidents within the people are affected by external factors and evolve into a social turmoil that conflicts with the enemy.

\section{THE INTERNET PUBLIC OPINION AND THE PREVENTION OF GROUP EVENTS OF COLLEGE STUDENTS IN THE NEW MEDIA ENVIRONMENT}

Colleges and universities management departments should pay full attention to the management and monitoring of Internet public opinion, guidance, and minimize the negative impact of Internet public opinion, so as to prevent mass incidents in colleges and universities to safeguard the stability of the university escort.

\section{A. Universities should Establish a Network Public Opinion Monitoring Mechanism.}

At present, colleges and universities have established a set of network management systems, but they are basically only focused on hardware management such as network construction. The management and monitoring of network public opinion are still less involved. Although some colleges and universities have established network content management mechanisms, they only hand over the management of network public opinion to the propaganda department. The main content of management is generally limited to the review of online content, and there are few individuals responsible for the dissemination of information on the network. At the time of disposal, the efficiency is low, and valuable response opportunities are lost because of the layers of reporting. Therefore, a special network sentiment handling team should be set up to take charge of the leadership of the branch of the branch, including the participation of school functional departments such as the propaganda department, network center, student office, and Youth League committee. If any Internet public opinion incidents are discovered, the joint meetings of various departments should be held in time to work together and deal with them in a timely manner so as to solve the problem in the bud.

\section{B. Taking the Advantages of New Media to Increase the Positive Guidance on Internet Public Opinion and quickly Control the Situation.}

Universities can employ a group of web opinion leaders, such as webmasters, webmasters, moderators, and outstanding writers who have certain political discernment, textual expression, and popularity, and organize a propaganda team, who has conducted positive public opinion guidance on the majority of students in online 
forums, microblogs, and message centers to promote the development of online public opinion. Facts have proved that it is a very effective method of guiding the public opinion of the Internet, which can minimize the negative public opinion and prevent the occurrence of group incidents in college students.

\section{Establish Emergency Response Mechanisms for Online and Offline Linkages in Mass Incidents in Colleges and Universities.}

After the public opinion-induced college mass incidents occur, it is necessary to establish an online and offline emergency response mechanism for group events. At the same time, it is necessary to unblock channels and communicate with netizens and the outside world in a timely manner. In the process of dealing with group incidents, it is necessary to publish facts and information in a timely manner on the Internet, and ensure that information is published accurately, objectively, and comprehensively, stabilizing the school's order, sparing supervisors' emotions, and avoiding unnecessary panic and turmoil. At the same time, it is necessary to strengthen contact with social media to ensure fairness, fairness and openness in the handling of incidents, eliminate suspicions from outside, and safeguard the school's good reputation and image. In the process of group events in colleges and universities, colleges and universities will inevitably deal with the media, and passively or actively accept the supervision of media. [5] In this situation, colleges and universities should have a positive attitude towards the media and try to guide the correct public opinion and eliminate the negative impact of the incident on colleges and universities. It's important to open information. Covering can only lead to more arbitrary guesses and arbitrary judgments by the media, and lead to further expansion of the situation, which is worse and worse. This is a valuable lesson learned from the failure of many domestic universities in the face of media in mass incidents. After the group incidents are resolved, colleges and universities should resume normal teaching life order as soon as possible, and publish and feedback information on the Internet, carry out comments and guidance, guide teachers and students of colleges and universities to correctly understand the group incidents, and eliminate the negative impact of the incident on colleges and universities. At the same time, colleges and universities should further strengthen the dissemination and monitoring of Internet public opinion in colleges and universities, and prevent criminals from maliciously speculating, provoking dissatisfaction with group events, and preventing repeated incidents.

\section{REFERENCES}

[1] Dongmei LIU: An Analysis of the Legal Relations of Colleges and Universities, Modern Education Science, No. 1,2015

[2] Xijiang WANG: Typology and Development Trends of Group Events, Yangtze River Forum, No. 4, 2016.

[3] Zhanjun WANG, Definition and Multidimensional Analysis of Group Events, Journal of Political and Legal Sciences, No. 5, 2016.

[4] Huimin QIN, Reflections on Certain Issues in Legal Disputes in Colleges and Universities, Jurist, No. 5, 2015.

[5] Qing XU: Protection of the rights of university students and the rule of law, Exploration of Higher Education, No. 6,2015 